\title{
Perceptions and short-term experiences of newly qualified radiographers performing compulsory community service
}

\author{
L. Dlamini*, L. Sekoli, P. Bresser
}

Department of Radiography, Faculty of Health Sciences, School of Healthcare Sciences, University of Pretoria, South Africa

* Corresponding author. Department of Radiography, Faculty of Health Sciences, University of Pretoria, HW Snyman Building North, Room 4-33 Bophelo Road Gezina, Pretoia, South Africa. E-mail address: dlamini.lungile@gmail.com (L. Dlamini).

\section{Highlights}

- CCS was regarded as a beneficial policy where objectives of the policy and job expectations were clear among radiographers.

- Newly qualified radiographers felt it necessary to be given orientation and mentorship when commencing CCS.

- Adjusting to the workload and orientation issues in the CCS setting were identified as the main transition difficulties.

\begin{abstract}
Introduction: Compulsory community service (CCS) is a concept that was adopted by many countries as a strategy to address the shortage of health workers. CCS was initiated in 1997 in the South African healthcare system to alleviate improper distribution of health workers in the public sector. CCS experiences of various health professions excluding radiographers were explored where debates regarding the impact, experiences and perceptions of the CCS year are ongoing. This study aimed to describe the perceptions and short-term experiences of newly qualified radiographers performing CCS in Gauteng, South Africa.

Methods: A cross sectional descriptive study was conducted using a questionnaire distributed to 81 newly qualified radiographers who had started CCS in the Gauteng province in 2017 across 11 radiology departments. A response rate of $48.1 \%(n=39)$ was obtained.

Results: Newly qualified radiographers understood the objectives of CCS and felt adequately prepared for their roles as CCS radiographers in terms of education skills acquired and role expectations. Participants felt confident to commence their duties and were not intimidated by their work environments. Orientation, mentoring and supervision were identified to be the main challenges during the CCS year.

Conclusion: The concept of CCS is widely accepted and regarded beneficial by CCS radiographers. Similar challenges emerged as reported by other health professionals despite the presence of role models. The development and implementation of structured guidelines regarding orientation and mentoring of CCS health professionals is strongly recommended to address the needs identified by this study.
\end{abstract}


Keywords: Community service, Radiographer experiences, Orientation, Mentoring

\section{Introduction}

The World Health Organisation (WHO) has forecast a shortfall of 18 million health workers by 2030, which is of great concern. ${ }^{1}$ It was reported that Africa has 2.3 health workers per 1000 population while America has 24.8 health workers per 1000 population. ${ }^{2}$ Globally, the shortage of skilled health workers is a recognised problem. Retention of skilled health workers confounds the problem as countries struggle to retain health workers as they migrate from less developed countries to more developed ones in search of greater career opportunities. ${ }^{3}$ Compulsory community service (CCS) is one strategy that was employed in over 70 countries as a way to retain and deploy the health workforce within the less developed countries. ${ }^{4} \mathrm{CCS}$ aims to consolidate newly qualified professionals' knowledge, skills, behaviour patterns and critical thinking whilst developing them professionally for their role as permanent staff. It also aims to ensure improved provision of health services to all citizens of the country. ${ }^{5}$

In South Africa, CCS is a one-year programme implemented by the Department of Health $(\mathrm{DOH})$, whereby newly qualified professionals are assigned to public hospitals to serve the public sector after completing their undergraduate study. During undergraduate training radiographers are placed in public or private institutions as part of work integrated learning (WIL) which is a core part of radiography curricula in the country. The WIL enables the undergraduate students to comply with the required clinical competency hours as stipulated by the regulating health board (Health Professions Council of South Africa). Since students undertake the WIL during their training they may acquire slightly different skill sets based on the type of patient, work environment and differing resources within the various contexts. Although the qualifications obtained are accredited by the South African Qualifications Authority (SAQA) and the Council of Higher Education (CHE) with approved standardised outcomes, the manner in which students reach the prescribed outcomes is unique to each institution's training programme. Therefore the CCS year could be viewed as a buffer for potential deficits in training and skills acquired during undergraduate training. The CCS year follows completion of the degree and its primary purpose is to render service in public hospitals, in both rural and urban areas. Although there are some similarities to what many term as an internship, the CCS year is not for clinical training purposes and therefore students are not assessed as they would have been during WIL. Radiographers do not work under the strict direct supervision as during WIL. On the contrary they serve as junior members of staff.

CCS was introduced into the healthcare system by the South African government in 1997 to address the shortage and improper distribution of health professionals within the public sector. 
6 It was first implemented in 1998, among the medical doctors, dental and pharmaceutical professions. This was followed in 2003 by a further eight professional groups (allied health professionals) which included radiographers, nurses, podiatrists, dieticians, music therapists, physiotherapists, therapeutic radiographers and speech and language therapists. Since the inception of CCS in South Africa, the experiences in other professions, such as dieticians ${ }^{7-8}$, speech-language therapists and audiologists ${ }^{9}$, physiotherapists ${ }^{10}$ and nurses ${ }^{5}$ have been investigated. Findings from these studies included the positive and negative aspects of the CCS year, experiences and perceptions of the professionals with profession specific recommendations regarding CCS were made.

Health institutions have welcomed professionals performing CCS as additional resources for the shortage of staff in the public sector (rural and urban). However, no structured guidelines have been provided at a regional level as to how these professionals should be utilised or managed during the CCS year, ${ }^{5}$ therefore no standardised set of expectations from radiographers as they begin their first year as professionals. It has been recommended that guidelines ought to be informed by the perceptions and experiences of CCS practitioners as well as CCS managers. ${ }^{11}$

There have been debates regarding the impact, experiences and perceptions of the CCS year among radiographers in South Africa since the initial inception of the policy. In clinical practice, the researchers observed a misperception and misunderstanding of the purpose and concept of CCS among the newly qualified radiographers. Those who trained in private sector as students, found the shift into the public sector during the CCS year unsettling. They raised concerns of the change in environment, x-ray equipment and different working protocols. Ultimately, they reported feeling as though the CCS year was not meant to benefit them as they were merely being utilized to close the gap in the public sector staff shortage. Some CCS radiographers questioned the role of CCS in improving their behaviour patterns, critical thinking, professional and clinical skills. Despite the implementation of the CCS year in South Africa 13 years ago, there is paucity in literature concerning the perceptions and experiences of radiographers about CCS in South Africa. This study aimed to investigate the perceptions and short-term experiences of newly qualified radiographers in Gauteng, the most populous province in South Africa, to contribute to the existing CCS evidence-base among allied health professions.

\section{Methods}

A cross sectional descriptive study was conducted in 11 radiology departments at tertiary and district public hospitals in Gauteng. Hospitals were selected based on the number of CCS 
radiographers allocated. In 2017, a total of 101 newly qualified radiographers were placed for CCS. At the selected hospitals, 81 of the CCS radiographers were invited to complete the self-administered questionnaire adapted from a similar study. ${ }^{12}$ One open ended question was added at the end of the questionnaire to allow space for additional comments regarding the CCS programme. The questionnaire was disseminated six months after the commencement of CCS. Ethical approval to conduct the study was obtained from the Faculty of Health Sciences Research Ethics Committee of the University of Pretoria (reference no. $447 / 2016$ ) and access to the hospitals was granted by the DOH.

\section{Data analysis}

Descriptive statistics were used to summarize the data in terms of frequencies and proportions. All analysis was done using STATA 14 (StataCorp, LLC, Texas, US) software. Responses to the five Likert scale categories ranging from "strongly disagree" to "strongly agree" were collapsed to form three categories comprising of positive, negative and neutral responses. The responses to the open ended question were analysed using thematic analysis. Common themes from data collected by both researchers were identified and grouped together. They are presented in the results according to the corresponding section in the questionnaire that the commentary was related to.

\section{Results}

Out of 81 CCS radiographers invited to participate in the study, a response rate of $48.1 \%$ $(n=39)$ was obtained. The majority of the participants were placed in their first choice hospital in an urban setting. Demographic information is provided in Table 1

Table 1: Newly-qualified radiographers' demographic data

\begin{tabular}{|c|c|c|}
\hline & $\mathrm{N}=39$ & Percentage \\
\hline \multicolumn{3}{|l|}{ Gender } \\
\hline Male & 12 & $30.8 \%$ \\
\hline Female & 27 & $69.2 \%$ \\
\hline \multicolumn{3}{|l|}{ Age group } \\
\hline $21-25$ years & 36 & $92.3 \%$ \\
\hline $26-30$ years & 3 & $7.7 \%$ \\
\hline \multicolumn{3}{|l|}{ Area } \\
\hline Urban & 28 & $71.1 \%$ \\
\hline Semi-urban & 11 & $28.9 \%$ \\
\hline \multicolumn{3}{|l|}{ Hospital Choice } \\
\hline $1^{\text {st }}$ & 26 & $66.7 \%$ \\
\hline $2^{\text {nd }}$ & 6 & $15.4 \%$ \\
\hline $3^{\text {rd }}$ & 5 & $12.8 \%$ \\
\hline $4^{\text {th }}$ & 1 & $2.6 \%$ \\
\hline $5^{\text {th }}$ & 1 & $2.6 \%$ \\
\hline
\end{tabular}


Perceptions of the CCS policy are indicated in table 2 while table 3 shows the perceptions of newly qualified radiographers in terms of their self-reported preparedness for their role as CCS radiographers.

Table 2: Newly qualified radiographers' perceptions of CCS

\begin{tabular}{lllll}
\hline Questions & $\mathbf{N}$ & Agree & Neutral & Disagree \\
\hline $\begin{array}{l}\text { 1. CCS is a good policy to retain radiographers in needed } \\
\text { areas. }\end{array}$ & $\mathrm{n}=39$ & $100 \%(39)$ & $0.0 \%(0)$ & $0.0 \%(0)$ \\
$\begin{array}{l}\text { 2. I understand the objectives of the CCS policy for } \\
\quad \text { radiographers }\end{array}$ & $\mathrm{n}=39$ & $82.1 \%(32)$ & $15.4 \%(6)$ & $2.6 \%(1)$ \\
3. I am satisfied with my allocated clinical site & $\mathrm{n}=38$ & $78.9 \%(30)$ & $18.4 \%(7)$ & $2.6 \%(1)$ \\
4. I know my job expectations as a CCS radiographer & $\mathrm{n}=39$ & $89.7 \%(35)$ & $10.3 \%(4)$ & $0.0 \%(0)$ \\
5. I feel I will personally benefit from CCS & $\mathrm{n}=39$ & $89.7 \%(35)$ & $5.2 \%(2)$ & $5.1 \%(2)$ \\
\hline
\end{tabular}

Overall the CCS policy was regarded as a beneficial policy where the objectives of the policy and job expectations are clear among the radiographers;

"It is a good program of introducing us to the real world." [S1.3]

"The CCS year is a good program as it allows us to tap into being individual personnel in the professional world of health care." [S2.2]

"It is helpful in making sure that one remains in or goes back to their respective provinces to assist with the problem of hospitals being short staffed." [S1.11]

Table 3: Perceptions of preparedness for the CCS radiographer role.

\begin{tabular}{lllll}
\hline Questions & N & Agree & Neutral & Disagree \\
\hline $\begin{array}{l}\text { 1. I can apply my radiography education to the clinical } \\
\text { settings }\end{array}$ & $\mathrm{n}=38$ & $94.7 \%(36)$ & $5.3 \%(2)$ & $0.0 \%(0)$ \\
$\begin{array}{l}\text { 2. I am confident with what I know to start my CCS } \\
\text { 3. I feel sufficiently ready to face the real world without my }\end{array}$ & $\mathrm{n}=38$ & $94.7 \%(36)$ & $5.3 \%(2)$ & $0.0 \%(0)$ \\
$\quad$ lecturers and tutors supervision & $\mathrm{n}=39$ & $94.9 \%(37)$ & $5.1 \%(2)$ & $0.0 \%(0)$ \\
$\begin{array}{l}\text { 4. I am able to carry out skills I acquired during my training } \\
\text { 5. I am comfortable to delegate tasks to students and other }\end{array}$ & $\mathrm{n}=38$ & $97.4 \%(37)$ & $2.6 \%(1)$ & $0.0 \%(0)$ \\
$\quad$ staff & $\mathrm{n}=39$ & $74.4 \%(29)$ & $17.9 \%(7)$ & $7.7 \%(3)$ \\
6. I have no difficulty in prioritizing patient care needs & $\mathrm{n}=39$ & $89.7 \%(35)$ & $7.7 \%(3)$ & $2.6 \%(1)$ \\
7. I am not overwhelmed by patient care responsibilities and & $\mathrm{n}=39$ & $76.9 \%(30)$ & $20.5 \%(8)$ & $2.6 \%(1)$ \\
$\quad$ & & & & \\
\hline
\end{tabular}


Radiographers felt they were sufficiently prepared for their role as CCS radiographers as most felt they were able to apply their radiography education to the clinical setting and were able to carry out their skills.

"The CCS program is necessary to put us out of our comfort zone and expand our knowledge outside our training hospitals." [S1.5]

'Community service was a good learning experience for me since I trained at a private practice." [S2.12]

There were however different opinions about skills development and application of skills among the participants.

"senior radiographers expect a lot from us." [S1.16] and "they expect us to do too much." [S2.16]

"CCS radiographers are side-lined. Senior radiographers isolate themselves and CCS radiographers are treated as students. CCS radiographers are not given any duties which requires responsibility and accountability." [S1.10]

My concern is about the work allocation, we are not allocated at CT and fluoroscopy, we only do general work" [N1.10] and "The training one receives during CCS is limited, since every hospital regards us as part-time workers who are leaving / whose contract expires in a year. So they see no reason in training us for anything." [S2.7]

The perceptions and experiences of orientation to CCS, mentoring in the CCS year and support offered for CCS radiographers are presented in table 4.

Table 4: Newly-qualified radiographers' perceptions regarding orientation, mentoring and support

\begin{tabular}{|c|c|c|c|c|}
\hline Questions & $n$ & Agree & Neutral & Disagree \\
\hline $\begin{array}{l}\text { 1. It is necessary to be given orientation by the health care } \\
\text { institution on arrival to do CCS. }\end{array}$ & $n=39$ & $92.3 \%(36)$ & $5.1 \%(2)$ & $2.6 \%(1)$ \\
\hline $\begin{array}{l}\text { 2. I think mentorship is necessary for everyone } \\
\text { commencing CCS }\end{array}$ & $n=39$ & $97.7 \%(30)$ & $17.9 \%(7)$ & $5.1 \%(2)$ \\
\hline $\begin{array}{l}\text { 3. My mentor is supportive towards my adjustment in the } \\
\text { health care institution }\end{array}$ & $n=39$ & $48.7 \%(19)$ & $41.0 \%(16)$ & $10.3 \%(4)$ \\
\hline $\begin{array}{l}\text { 4. I am at ease in asking for help from the mentor/ } \\
\text { registered radiographer in the department }\end{array}$ & $n=39$ & $76.9 \%(30)$ & $17.9 \%(7)$ & $5.1 \%(2)$ \\
\hline
\end{tabular}




\begin{tabular}{|c|c|c|c|c|}
\hline $\begin{array}{l}\text { 5. I am supported by my senior radiographers in the } \\
\text { department }\end{array}$ & $n=39$ & $66.7 \%(26)$ & $23.1 \%(9)$ & $10.3 \%(4)$ \\
\hline $\begin{array}{l}\text { 6. There are positive role models for me to observe in my } \\
\text { department }\end{array}$ & $n=39$ & $71.8 \%(28)$ & $15.4 \%(6)$ & $12.8 \%(5)$ \\
\hline $\begin{array}{l}\text { 7. My department manager gives me encouragement and } \\
\text { feedback about my work performance }\end{array}$ & $n=39$ & $35.9 \%(14)$ & $33.3 \%(13)$ & $30.8 \%(12)$ \\
\hline
\end{tabular}

Newly qualified radiographers felt it was necessary to be given orientation and mentorship when commencing CCS. Although general orientation was provided for all health professions, the radiographers reported the need for profession specific orientation within the relevant environment. While most felt at ease and supported in their work places, others disagreed.

"It is a very good program. I appreciate all the mentorship and guidance I have been provided." [S2.10]

"There wasn't a thorough orientation for the CCS year. [N1.15] I knew I had to do this out of compulsion, but I really did not know why." [S1.21]

"My hospital does not have an HOD (Head of Department). I find it difficult to ask questions because I never get relevant answers. There is lack of communication and structured protocols without reasons why we follow them. For example, no one explained how we should apply for annual leave and sick leave. There is too much politics in here, it is rough." [S1.19]

"Mentors do not really follow up on our work or ask if we are okay.'[S2.5]

Figure 1 indicates the experiences of CCS radiographers with regard to satisfaction in the work environment. 


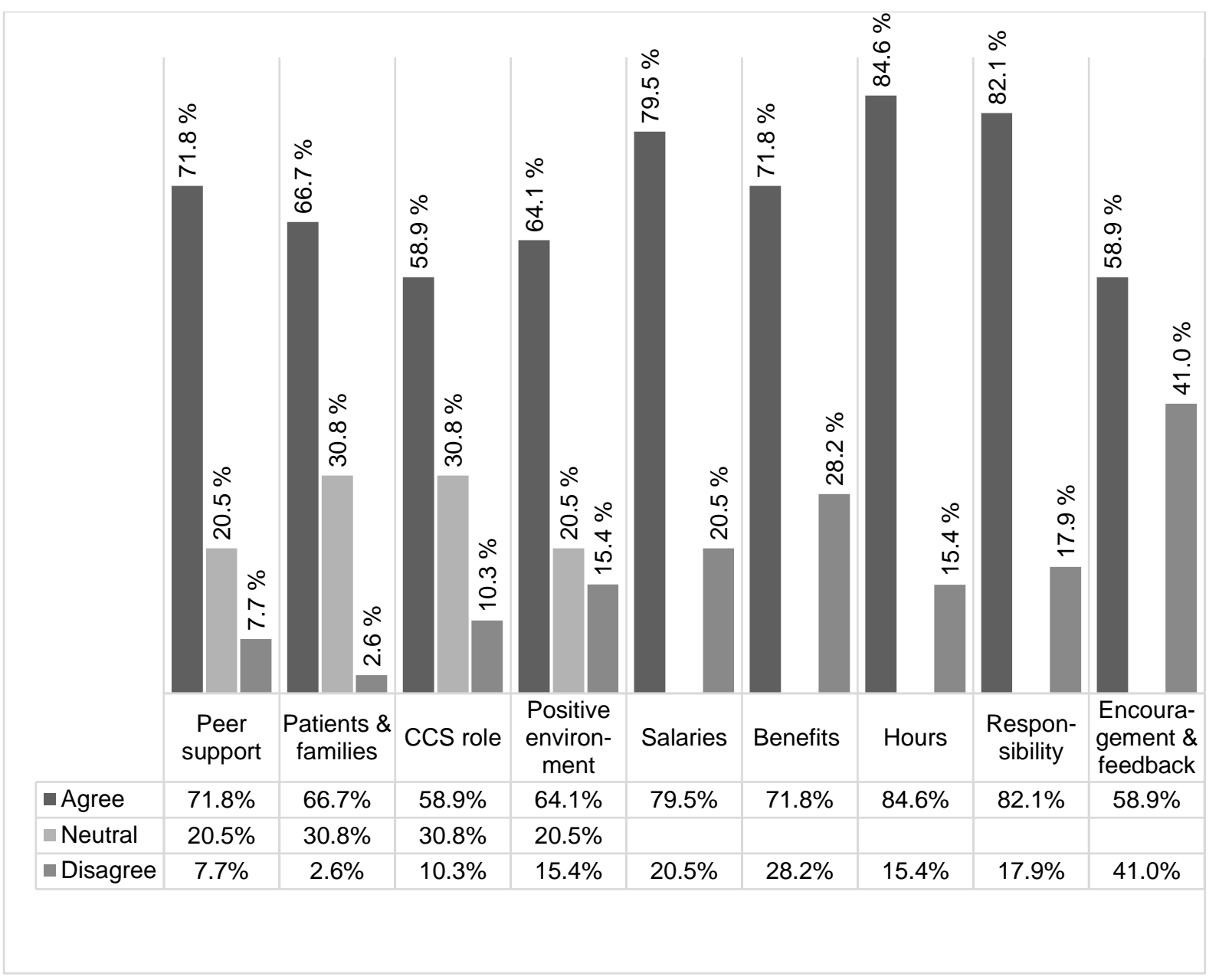

Figure 1: Most satisfying aspects of work environment

Radiographers were satisfied with peer support, interacting with patients and making a difference. CCS radiographers felt they had made a difference in the communities they served. Radiographers were least satisfied with outdated facilities $(43.60 \%)$ and equipment, orientation (30.8\%) and lack of teamwork. Interpersonal relationships proved to be the most common least satisfying factor with $48.70 \%$ participants identifying it as a challenge.

"The machines we use are far different from the ones we used when I was a student."[N1.15]

"These machines are broken most of the times [N1.12] and equipment does not work for many years now, very frustrating." [N1.20]

Transition difficulties such as role expectations, confidence, workload and orientation are illustrated in figure 2. Adjusting to the workload and orientation issues in the CCS setting were identified as the main transition difficulties while role expectations and lack of confidence did not play a major role in transition difficulties. 


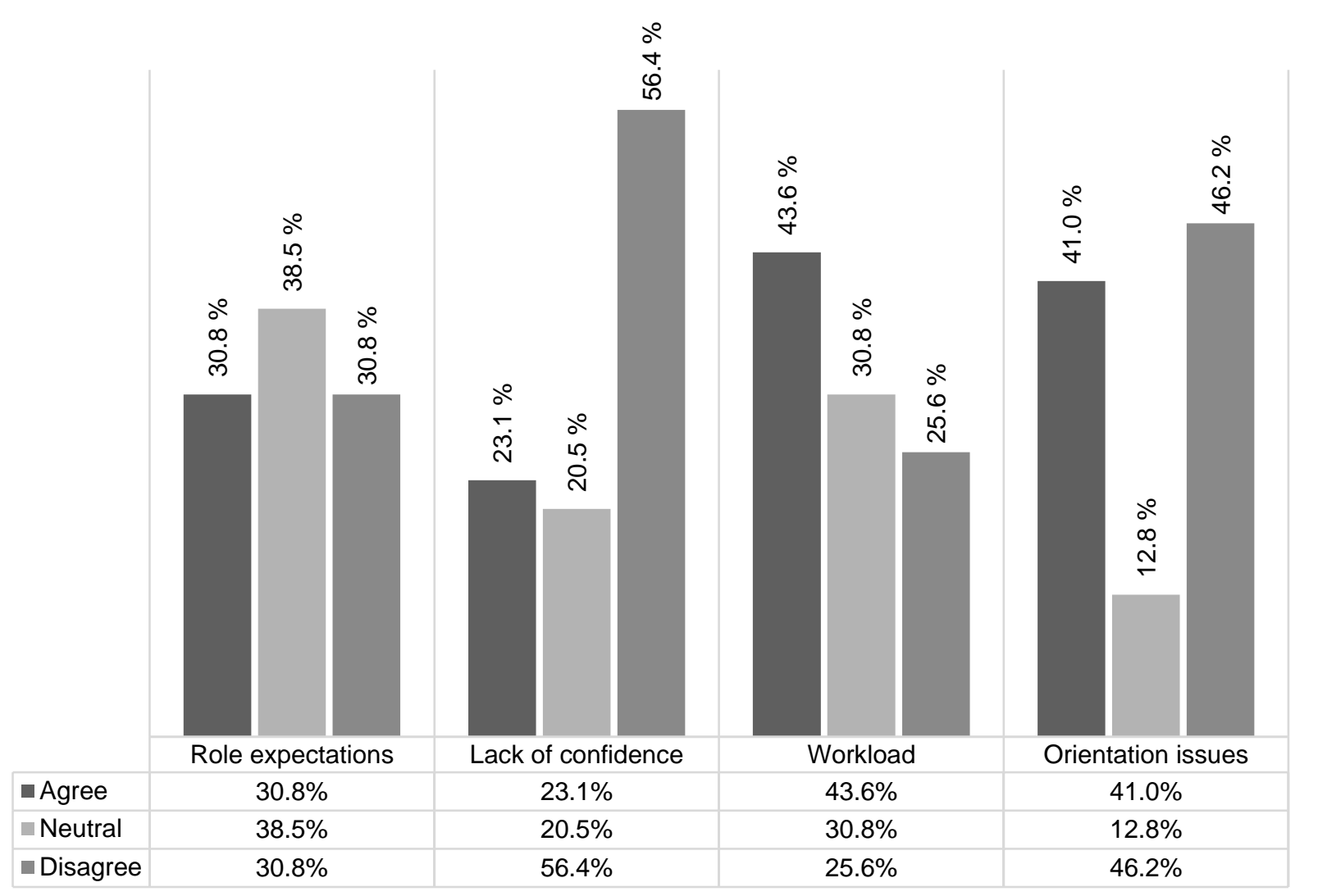

Figure 2: Transition difficulties among the CCS radiographers

\section{Discussion}

The objectives of community service were well understood by radiographers. This is seen in the positive number of radiographers conforming to this statement. All participants thought the CCS policy is a good policy to enhance skill development and exposure to a real world environment. Most of them were aware of their job expectations based on their prior WIL and felt they would personally benefit from the CCS. These results concurred with a similar study where nurses felt they understood the objectives of the CCS policy well, ${ }^{5}$ however there was dissatisfaction in terms of infrastructure and lack of resources by radiographers.

Almost all the participants felt they were able to apply their radiography education to the clinical setting. They felt sufficiently prepared for their CCS role and in their ability to offer radiography services with confidence. Liang et al found that newly qualified radiographers perceived themselves as sufficiently prepared for clinical practice. ${ }^{12}$ Similarly speech therapists felt the necessary skills had been provided by their training and also had the necessary knowledge provided by their education to begin their CCS. ${ }^{9}$ Doody et al. highlighted that sufficient preparation promotes smooth transition to the world of work. ${ }^{13}$ In contrast, it was revealed in 
this study that the highest factors that could have affected transition to the real world for other participants was predominantly the workload and lack of orientation. The workload difficulties experienced by the participants were similar to what Kramer described as reality shock ${ }^{14}$, which new workers experience in spite of spending many years preparing for the work they would eventually perform.

Lack of sufficient orientation was shown as one of the contributing factors for a lack of confidence in newly qualified radiographers. According to Duteau orientation is necessary for positive socialization into the profession. ${ }^{15}$ Orientation is important because it lays a foundation for the new employee's entire career with the department. In this study however, even though participants thought it was necessary to be given orientation, there was no concern regarding lack of confidence. The majority of participants thought that mentorship is necessary for everyone commencing CCS. The lack of mentoring/supervision might be unfavorable to the development of a newly qualified professional. ${ }^{9}$ Therefore there should be more standardized education for mentors within the department. The first few years of one's career are important for cultivating good habits, favorable attitudes and proper work ethics. If these habits are not cultivated early in one's career, it may be difficult to eradicate undesirable habits without a competent and exemplary role model present.

Participants felt supported by senior radiographers in the departments. Satisfaction with regards to support and supervision was also rated highly by doctors and dentists in a study by Hatcher et al. ${ }^{11} \mathrm{CCS}$ radiographers also felt at ease when seeking help from their seniors and mentors in the x-ray departments. Rush et al. ${ }^{16}$ recommended that, those who mentor newly qualified professionals should be trained to do so. Radiographers were mostly satisfied with peer support, interacting with patients and making a difference. The results show that CCS radiographers felt they had made a difference in the communities they served. These results are consistent with other studies in South Africa, as demonstrated by psychologists where $90 \%$ felt they contributed positively to their allocated community. ${ }^{17}$ Despite these satisfying factors in the work environment, infrastructure played a large role in dissatisfaction. Radiographers were least satisfied with outdated facilities and equipment, small workspace and paperwork.

Interpersonal relationships were also proven to be least satisfying including lack of recognition. The lack of recognition concurred with the results found in a study by Manyisa, whereby participants echoed the problem of poor infrastructure in public hospitals. ${ }^{18}$ Lack of orientation and inconsistent mentors was also seen to be least satisfying. This response can be related to the study by Dyess et al. study where nurses reported numerous instances of feeling utterly alone and influencing feelings of professional isolation. ${ }^{19}$ 
The Institute for Employment Research in the United Kingdom proposed that one response to the variety of work is to use job rotation to help the newly qualified professional to develop the ability to apply their skills in a range of contexts. They also emphasized that there is a strong tradition of learning through working within radiography and physiotherapy such that you do not become fully experienced until several years after your formal qualification. ${ }^{20}$

\section{Conclusion}

CCS is well accepted and understood by CCS radiographers as an opportunity to equip newly qualified radiographers with valuable work experience and the confidence to work as an independent practitioner. The majority of participants understood that the objectives of the CCS year was to consolidate their skills and competence as professionals.

Newly qualified radiographers reported perceptions of high levels of competency to apply their radiography education in the clinical setting and readiness to face the real world on their own. The positive factors perceived and experienced in six months included peer support and making a difference in the patients' lives.

The negative factors perceived and experienced in six months included lack of supervision and mentoring, lack of orientation, poor working systems and overwhelming workload. It is acknowledged that the sample was limited to an urban and semi urban area therefore the results may not be generalizable to those outside the region. It is recommended that the above issues are addressed through the development and implementation of a structured mentorship program for seniors to support CCS radiographers. Such support will promote their development; thereby enhancing their benefit to the communities they serve and also promote a healthy working environment for the newly qualified staff members which might encourage them to stay beyond the CCS year. Such a mentorship programme could include clear expectations of what is expected from all participants. These include, fixed mentorship meetings, an induction program, communication channels, regular feedback regarding performance, opportunities for personal development and exit interviews for radiographers at the end of the programme. Furthermore, development of guidelines for the CCS year should be informed by the current experiences and perceptions of health care workers at the start of their careers.

\section{Conflict of interest}

The authors report no declaration of conflict of interest. The authors alone are responsible for the writing and content of this paper. 


\section{References}

1. Darzi A, Evans T. The global shortage of health workers-an opportunity to transform care. The Lancet. 2016; 388(10060):2576-2577.

2. Naicker S, Plange-Rhule J, Tuff RC and Eastwood JB. Shortage of health care workers Africa. Ethnicity and disease. Ethn Dis. 2009 Spring;19(1 Suppl 1):S1-60-4

3. Kuehn B. Global Shortage of Health Workers, Brain Drain Stress Developing Countries. JAMA. 2007; 298(16):1853.

4. Frehywot S, Mullan F, Payne PW and Ross H. Compulsory service programmes for recruitment health workers in remote rural areas: Do they work?. Bulletin of the World Health Organization. 2010; 88(5):364-370.

5. Govender S, Brysiewicz P, Bhengu B. Perceptions of newly-qualified nurses performing compulsory community service in Kwazulu-Natal. Curations. 2015; 38(1).

6. Republic of South Africa, 1997 Medical, dental and supplementary health service professions Amendment Act, 1997(Act No. 89 of 1997; Notice No. 1644 of 1997), Government Gazette 390 (18 540), Government Printers, Cape Town. 2016.

7. Parker W, Steyn N, Mchiza Z, Wentzel-Viljoen E, Dannhauser A, Mbhenyane X et al. Challenges of efficient health service delivery: experiences of dieticians completing their compulsory community service year in South Africa. Public Health Nutrition. 2011;15(08):1411-1418.

8. Visser J, Marais M, du Plessis J, Steenkamp I, Troskie I. Experiences and attitudes of dieticians during the first compulsory community service year (2003). SAJCN. 2006; 19(1):10-17.

9. Wranz E. Compulsory Community Service for Speech-language and Hearing Therapy Professionals: Readiness, Reality and Readjustment. University of Stellenbosch, South Africa. 2011.

10. Mostert-Wentzel K, Frantz J, Van Rooijen A. A model for community physiotherapy from the perspective of newly graduated physiotherapists as a guide to curriculum revision. AJHPE. 2013; 5(1):19.

11. Hatcher A, Onah M, Kornik S, Peacocke J, Reid S. Placement, support, and retention of health professionals: national, cross-sectional findings from medical and dental community service officers in South Africa. Human Resources for Health. 2014; 12(1).

12. Liang, W Tan; Reed, W and Agudera, M. Preparedness for Clinical Practice - Perceptions of Newly Qualified Radiographers [online]. Radiographer: The Official Journal of the Australian Institute of Radiography. 2010; 57(3):22-28.

13. Doody, O., Tuohy, D. \& Deasy, C, 'Final-year student nurses' perceptions of role transition', British Journal of Nursing 2012; 21(11):684-688. 
14. Kramer M. Reality Shock: Why nurses leave nursing. C.V. Mosby Company, St Lois.

15. Duteau, J. 'Making a difference: The value of preceptorship programs in nursing education', Journal of Continuing Education in Nursing. 2012; 43(1):37-43.

16. Rush, K.L., Adamack, M., Gordon, J., Lilly, M. \& Janke, R. 'Best practices of formal new graduate nurse transition programs: An integrative review', International Journal of Nursing Studies. 2013; 50(3):345-356.

17. Pillay A, Harvey B: The experiences of the first South African community service clinical psychologists. South African J Psychol. 2006; (36):259-280.

18. Manyisa Z M. The Current Status of Working Conditions in Public Hospitals at a Selected Province, South Africa: Part 2 J Hum Ecol, 2016; 56(1,2):220-231

19. Dyess, S.M. \& Sherman, R.O. 'The first year of practice: New graduate nurses' transition and learning needs', Journal of Continuing Education in Nursing. 2009; 40(9):403-410.

20. Warwick Institute for Employment Research, University of Warwick. What is effective career guidance? Evidence from longitudinal case studies in England. 2005 (78). 